\title{
The association of cervical sagittal alignment with adjacent segment degeneration
}

\author{
Xiaoyu Yang ${ }^{1}\left(\mathbb{D} \cdot\right.$ Ronald H. M. A. Bartels ${ }^{2} \cdot$ Roland Donk $^{3} \cdot$ Mark P. Arts $^{4} \cdot$ Caroline M. W. Goedmakers $^{1}$. \\ Carmen L. A. Vleggeert-Lankamp ${ }^{1}$
}

Received: 7 February 2019 / Revised: 5 September 2019 / Accepted: 16 September 2019 / Published online: 12 October 2019

(C) The Author(s) 2019

\begin{abstract}
Purpose Cervical spine surgery may affect sagittal alignment parameters and induce accelerated degeneration of the cervical spine. Cervical sagittal alignment parameters of surgical patients will be correlated with radiological adjacent segment degeneration (ASD) and with clinical outcome parameters.

Methods Patients were analysed from two randomized, double-blinded trials comparing anterior cervical discectomy with arthroplasty (ACDA), with intervertebral cage (ACDF) and without intervertebral cage (ACD). C2-C7 lordosis, T1 slope, $\mathrm{C} 2-\mathrm{C} 7$ sagittal vertical axis (SVA) and the occipito-cervical angle (OCI) were determined as cervical sagittal alignment parameters. Radiological ASD was scored by the combination of decrease in disc height and anterior osteophyte formation. Neck disability index (NDI), SF-36 PCS and MCS were evaluated as clinical outcomes.

Results The cervical sagittal alignment parameters were comparable between the three treatment groups, both at baseline and at 2-year follow-up. Irrespective of surgical method, C2-C7 lordosis was found to increase from $11^{\circ}$ to $13^{\circ}$, but the other parameters remained stable during follow-up. Only the OCI was demonstrated to be associated with the presence and positive progression of radiological ASD, both at baseline and at 2-year follow-up. NDI, SF-36 PCS and MCS were demonstrated not to be correlated with cervical sagittal alignment. Likewise, a correlation with the value or change of the OCI was absent. Conclusion OCI, an important factor to maintain horizontal gaze, was demonstrated to be associated with radiological ASD, suggesting that the occipito-cervical angle influences accelerated cervical degeneration. Since OCI did not change after surgery, degeneration of the cervical spine may be predicted by the value of OCI.
\end{abstract}

NECK trial Dutch Trial Register Number NTR1289.

PROCON trial Trial Register Number ISRCTN41681847.

\section{Graphic abstract}

These slides can be retrieved under Electronic Supplementary Material.

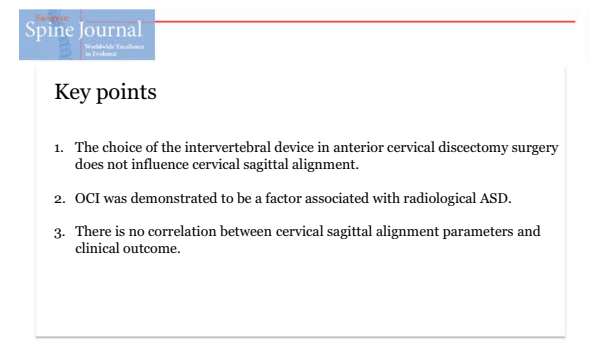

Yang X, Bartels RHMA, Donk R, Arts MP, Goedmakers CMW, Vleggert-Lankamp CLA,
(2019) The Association of Cervical Sagittal Alignment with Adjacent Segment Degeneration.
Eur Spine Jinger
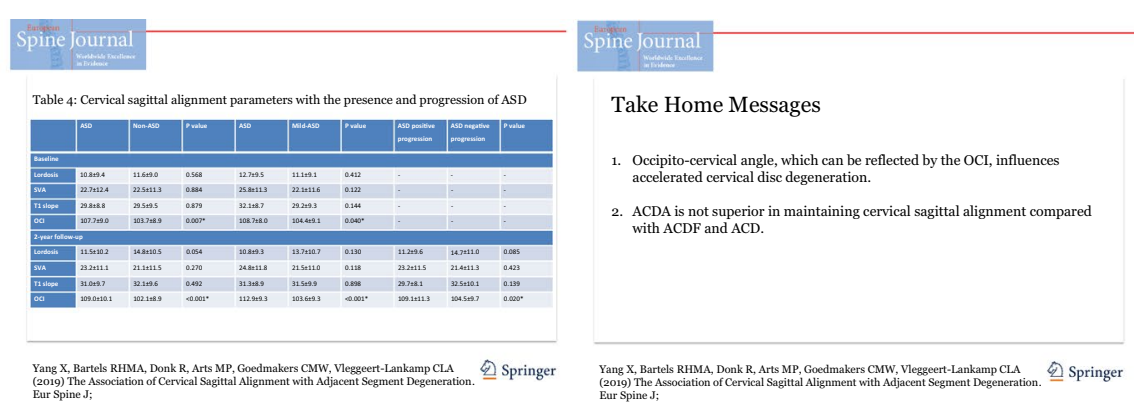

Electronic supplementary material The online version of this article (https://doi.org/10.1007/s00586-019-06157-0) contains supplementary material, which is available to authorized users.

Extended author information available on the last page of the article 
Keywords Cervical sagittal alignment $\cdot$ Cervical lordosis $\cdot$ Sagittal vertical axis $\cdot$ T1 slope $\cdot$ Adjacent segment degeneration

\section{Introduction}

The cervical spine has a crucial role in compensating a distorted global spinal balance. In order to maintain horizontal gaze, the cervical spine will compensate [1]. Regularly, global sagittal imbalance is only present in a very mild form, and subsequently, cervical compensation is only minor. However, even minor cervical spine balance compensation mechanisms may cause accelerated degeneration of the cervical spine segments (ASD). Surgical interventions that possibly interfere with sagittal alignment, like anterior discectomy, may influence ASD, irrespective of the presence of preoperative sagittal imbalance of the whole spine.

In order to quantify cervical spine sagittal alignment, several radiographic parameters have been proposed, including C2-C7 lordosis, C2-C7 sagittal vertical axis (SVA) and T1 slope $[2,3]$. It has to be realized though that these parameters also importantly influence each other $[4,5]$.

Furthermore, occipito-cervical inclination (OCI), defining the occipito-cervical angle, independent of the occipito-cervical distance, is an important sagittal alignment parameter, since it represents the stress on the cervical spine to maintain horizontal gaze [6]. To the best of our knowledge, no study correlated this parameter with cervical ASD previously.

Anterior cervical discectomy and fusion (ACDF) has been a common surgical treatment for cervical radiculopathy since it was initially described in the 1950s [7, 8] and became the gold standard procedure. Recently, artificial disc implantation (ACDA) has been proposed to maintain disc height, restore cervical motion and avoid neck pain and disability in post-surgical follow-up [9]. Limited studies have described the cervical sagittal alignment after ACDA in comparison with ACDF and reported contradictory results. Kim et al. [10] reported that ACDA maintained the cervical sagittal alignment well in comparison with ACDF, but other researchers disputed this advantage and found that the alignment of the cervical spine is unaltered irrespective of the anterior cervical discectomy procedure performed [11, 12]. Most studies, however, only focused on comparing the cervical curvature between ACDF and ACDA, and the other sagittal alignment parameters were rarely investigated.

In the current study, sagittal alignment parameters of the cervical spine are evaluated in patients from two randomized double-blind trials on patients treated by anterior cervical discectomy with or without interbody fusion and arthroplasty for cervical radiculopathy at baseline and a 2-year follow-up. The parameters and the changes in sagittal alignment were correlated with the incidence and progression of radiological ASD and to clinical outcomes.

\section{Materials and methods}

\section{Study design}

\section{NECK trial}

A prospective, randomized double-blind multicentre trial among patients with cervical radiculopathy due to single-level disc herniation was conducted. Patients were randomly assigned into three groups: anterior cervical discectomy with arthroplasty (ACDA; activ ${ }^{\circledR} \mathrm{C}$, Aesculap AG, Tuttlingen, Germany), anterior cervical discectomy with fusion (ACDF; Cage standalone) and anterior cervical discectomy (ACD). The protocol was approved by medical ethics committees, including an approval for randomization after anaesthetic induction. All patients gave informed consent.

The design and study protocol were published previously [13]. The 2-year follow-up data revealed no differences in clinical outcomes [14].

\section{PROCON trial}

The trial design was a prospective, double-blind, singlecentre randomized study, with a three-arm parallel group. Patients were randomly allocated into three groups: ACDA (Bryan disc prosthesis, Sofamor Danek, Kerkrade, the Netherlands), ACDF (Cage standalone, DePuy Spine, Johnson and Johnson, Amersfoort, the Netherlands) and ACD. The trial was approved by the medical ethics committee. All patients gave informed consent.

The design and study protocol were published previously [15]. The follow-up data up to 8 years post-surgery revealed no differences in clinical outcomes [16].

\section{Radiological evaluation}

Lateral X-rays of the cervical spine were obtained with the patients in a standing position and instructed to look straight ahead, with hips and knees extended, in order to obtain a neutral position of the head.

\section{Sagittal alignment parameters}

Cervical sagittal alignment parameters were measured preoperatively and 2 years post-operatively (Fig. 1): 


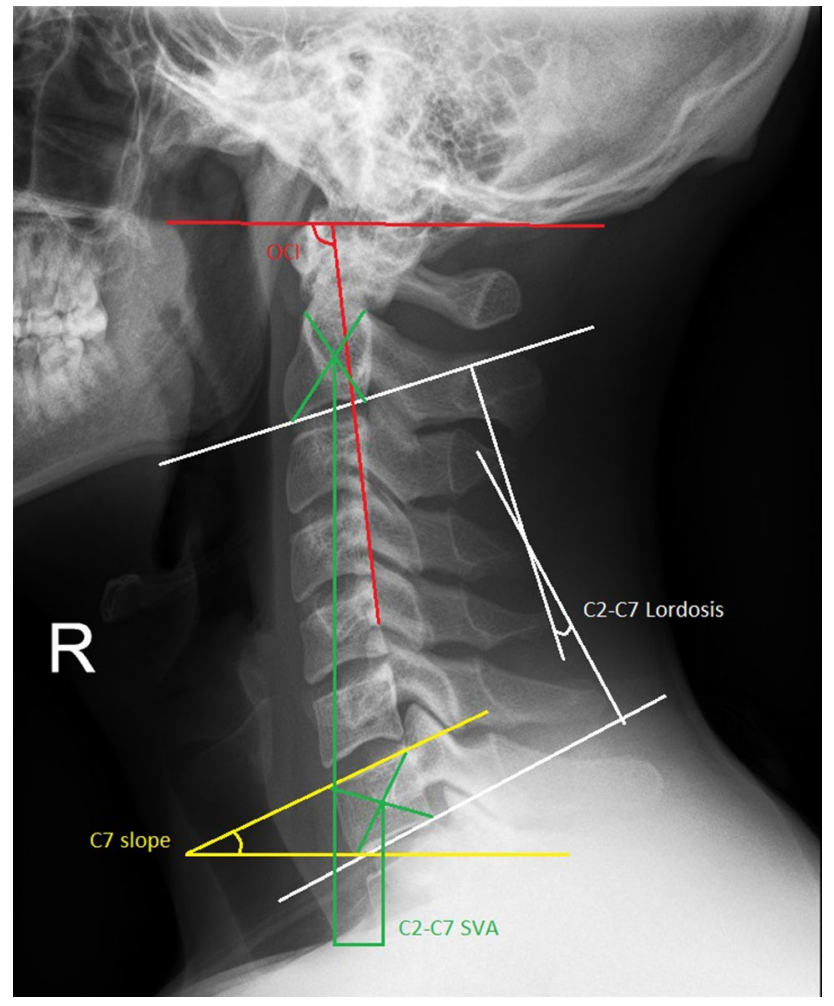

Fig. 1 Radiographic evaluation of cervical sagittal alignment parameters

- C2-7 lordosis: the angle as measured between the lines drawn parallel to the caudal endplate of $\mathrm{C} 2$ and $\mathrm{C} 7$.

- C2-7 SVA: distance between a plumb line from the centre of the $\mathrm{C} 2$ vertebra to the plumb line from the centre of $\mathrm{C} 7$ vertebra.

- T1 slope: since the superior endplate of T1 vertebra is invisible for most patients, C7 slope was measured as the angle between the superior endplate of $\mathrm{C} 7$ and a horizontal reference line. Subsequently, this angle was converted to the T1 slope using the formula: $\mathrm{T} 1$ slope $=(\mathrm{C} 7$ slope + 0.54)/0.88 [17].
- OCI: the angle formed by the line connecting the posterior vertical border of the $\mathrm{C} 4$ vertebral body and McGregor's line [6].

The changes of sagittal parameters after surgery, with reference to the baseline values, were investigated as well.

In the ACD group, the disc height decreased from the preto the post-operative situation. This might therefore influence the sagittal alignment parameters. Additionally, for this group specifically, the disc height was correlated with the baseline and 2-year follow-up alignment parameters as well.

\section{Adjacent segment degeneration}

ASD was defined based on the height of an adjacent level disc and the anterior osteophyte formation on X-rays according to the classification reported by Goffin et al. [18] preoperatively and 24 months post-operatively (Table 1). Since there are no strict criteria to define ASD, evaluation of ASD was performed with three different methods. Firstly, only if neither the superior nor inferior adjacent level demonstrated loss of disc height or anterior osteophyte formation, the patient was graded as 'non-ASD'; all other patients were graded as 'ASD'. Secondly, in a separate analysis, 'mild ASD' was scored if patients had 'no' or 'minor' ASD changes in both the superior and inferior adjacent levels, and 'ASD' was defined to be present if the classification was 'moderate' or 'severe' loss of disc height or anterior osteophyte formation in either the superior or inferior level. Thirdly, ASD was evaluated by progression of adjacent level degeneration: 'ASD progression' was marked as positive or negative for patients that did or did not increase in Goffin score during follow-up.

\section{Clinical outcomes}

NDI is a 10-item questionnaire on 3 different aspects: pain intensity, daily work-related activities and non-workrelated activities. Each item is scored from 0 to 5, and the total score ranges from 0 (best score) to 50 (worst score).
Table 1 The classification of adjacent segment degeneration

\begin{tabular}{lll}
\hline & Disc height & Anterior osteophyte formation \\
\hline $\begin{array}{l}\text { Normal } \\
\text { Mild }\end{array}$ & $\begin{array}{l}\text { Same as adjacent disc } \\
75-100 \% \text { of normal disc }\end{array}$ & $\begin{array}{l}\text { No anterior osteophyte } \\
\text { Just detectable anterior osteo- } \\
\text { phyte } \\
\text { Moderate }\end{array}$ \\
$\begin{array}{ll}\text { Clear anterior osteophyte }<25 \% \\
\text { of AP diameter of the cor- } \\
\text { responding vertebral body } \\
\text { Clear anterior osteophyte }>25 \% \\
\text { of AP diameter of the cor- } \\
\text { responding vertebral body }\end{array}$ \\
\hline
\end{tabular}

$A P$ anteroposterior 
This 50 points score was converted to a percentage (50 points $=100 \%$ ). The NDI is a modification of the Oswestry Low Back Pain Index and has been shown to be reliable and valid for patients with cervical pathology [19]. The physical-component summary (PCS) and mental-component summary (MCS) are derived from the SF-36 and are summary scores for, respectively, the Physical Quality of Life and the Mental Quality of Life. The PCS and MCS range from 0 to 100 , with higher scores representing better self-reported health.

\section{Statistical analysis}

All the data were presented as mean \pm standard deviation. Paired $t$ test was used to compare the changes of sagittal alignment parameters between baseline and 2-year follow-up data. Logistic regression analysis was used to determine the correlation between the sagittal balance parameters at baseline with the presence and progression of ASD. Likewise, logistic regression analysis was used to determine the correlation between the changes in sagittal balance parameters during the 2-year follow-up time. Linear regression analysis was used to correlate the disc height and cervical sagittal alignment parameters at baseline and at 2-year follow-up in the ACD group. Linear regression analysis was also performed to correlate the clinical outcome data with the sagittal balance parameters at 2-year follow-up in all groups. The correlations between sagittal alignment parameters were analysed using the Pearson correlation coefficient.
A $P$ value of $<0.05$ was considered significant. SPSS software, version 23.0, was used for all statistical analyses (SPSS, Inc., Chicago, IL, USA).

\section{Results}

In the current study, 253 patients were included and randomly assigned to ACD (83 patients), ACDF ( 85 patients) or ACDA ( 85 patients). At baseline, X-ray data were available for 228 patients and for 168 patients at 2-year follow-up.

\section{Demographics}

Baseline characteristics are presented in Table 2. The mean age of the study population was $45.2 \pm 7.3$ years, ranging from 27 to 70 years. There was no difference regarding baseline characteristics between treatment groups. Surgery was most frequently at levels C5-C6 and C6-C7.

\section{Characteristics of cervical sagittal alignment in subgroups}

Table 3 demonstrates the characteristics of the cervical sagittal alignment parameters in the different treatment arms. No differences were found regarding sagittal alignment parameters between the three surgical groups neither at baseline nor at 2-year follow-up $(P>0.05)$. Additionally, it was found that the cervical alignment parameters did not change significantly comparing baseline to post-operative values with the
Table 2 Patient demographics by treatment arm

\begin{tabular}{llllll}
\hline & ACD & ACDF & ACDA & Total & $P$ value \\
\hline Population & 83 & 85 & 85 & 253 & \\
Age (years, Mean \pm SD) & $45.3 \pm 6.7$ & $45.6 \pm 7.6$ & $44.8 \pm 7.7$ & $45.2 \pm 7.3$ & 0.787 \\
Body mass index (Mean \pm SD) & $26.2 \pm 3.8$ & $26.6 \pm 4.7$ & $26.7 \pm 4.1$ & $26.5 \pm 4.2$ & 0.726 \\
Gender & & & & 122 & 0.939 \\
Male & 42 & 37 & 43 & 131 & \\
Female & 41 & 48 & 42 & 118 & 0.305 \\
Smoking & & & & 133 & \\
Yes & 33 & 40 & 41 & & \\
No & 50 & 43 & 44 & & \\
Alcohol & & & & 98 & \\
Yes & 46 & 52 & 55 & 365 \\
No & 37 & 31 & 30 & 125 & \\
Herniated level & 1 & 2 & 0 & 124 & \\
C4-C5 & 46 & 39 & 40 & & \\
C5-C6 & 36 & 43 & 45 & 0 & \\
C6-C7 & 0 & 1 & & & \\
C7-Th1 & & & & & \\
\hline
\end{tabular}

$A C D$ anterior cervical discectomy, $A C D F$ anterior cervical discectomy with fusion, $A C D A$ anterior cervical discectomy with arthroplasty, $S D$ standard deviation 
Table 3 Characteristics of sagittal alignment parameters in subgroups

\begin{tabular}{lllll}
\hline & Lordosis & SVA & T1 slope & OCI \\
\hline Baseline & & & & \\
ACD (63) & $12.6 \pm 9.6$ & $21.9 \pm 12.9$ & $28.1 \pm 10.3$ & $105.7 \pm 9.1$ \\
ACDF (69) & $9.5 \pm 8.6$ & $23.5 \pm 11.2$ & $30.1 \pm 8.4$ & $104.6 \pm 9.5$ \\
ACDA (69) & $12.1 \pm 9.0$ & $22.1 \pm 10.8$ & $30.6 \pm 9.0$ & $104.7 \pm 8.7$ \\
$P$ value & 0.117 & 0.684 & 0.272 & 0.803 \\
2-Year follow-up & & & \\
ACD (48) & $13.5 \pm 9.8$ & $21.0 \pm 11.2$ & $30.7 \pm 10.1$ & $106.4 \pm 8.4$ \\
ACDF (48) & $11.8 \pm 11.1$ & $24.1 \pm 10.5$ & $33.1 \pm 8.7$ & $106.9 \pm 10.5$ \\
ACDA (57) & $13.6 \pm 10.5$ & $21.9 \pm 11.9$ & $30.6 \pm 10.0$ & $105.1 \pm 11.3$ \\
$P$ value & 0.634 & 0.376 & 0.349 & 0.663 \\
\hline
\end{tabular}

SVA sagittal vertical axis, $O C I$ occipito-cervical inclination, $A C D$ anterior cervical discectomy, $A C D F$ anterior cervical discectomy with fusion, $A C D A$ anterior cervical discectomy with arthroplasty

exception of $\mathrm{C} 2-\mathrm{C} 7$ lordosis in the ACDF group $(P=0.048)$. Irrespective of the surgical method, only $\mathrm{C} 2-\mathrm{C} 7$ lordosis was found to change (increase) significantly over 2 years (from $11.3^{\circ}$ to $13.1^{\circ}, P=0.023$ ). The other three parameters (OCI, C2-C7 SVA and T1 slope) did not change with a statistical significance. Notably, the angle or slope could be minimally negatively or minimally positively deviating.

\section{Correlation between disc height and cervical sagittal alignment}

In the ACD group, there was no correlation between the disc height of the target level and cervical sagittal alignment at baseline $(P>0.05)$. Likewise, this correlation was absent at 2 -year follow-up $(P>0.05)$. There was a decrease in disc height, but this did not impact overall balance.

\section{Adjacent segment degeneration (ASD)}

Preoperatively, the incidence of ASD did not differ in the three groups: $38 \%$ in the ACD group (27 patients), 36\% (29 patients) in the ACDF group and 29\% (22 patients) in the ACDA group $(P=0.428)$. At 2-year follow-up, ASD increased to $63 \%$ of patients in the ACD group (35 patients), and 55\% (28 patients) in the ACDF group and to $56 \%$ (34 patients) in the ACDA group. Likewise, between three groups, there was no statistically significant difference $(P=0.674)$.

If ASD was considered to be scored as 'ASD' only if disc degeneration and/or the presence of osteophytes was moderate or severe, the incidence of ASD was still comparable in the three treatment arms at baseline: $16 \%$ in the ACD group, $14 \%$ in the ACDA group and $13 \%$ in the ACDA group $(P=0.905)$. And likewise, 2 years after surgery, the incidence of ASD did not differ between three groups (29\% in the ACD group, $26 \%$ in the ACDF group and $20 \%$ in the ACDA group; $P=0.522$ ).

Furthermore, the progression of ASD was also investigated, comparing follow-up to baseline data. At 2 years after surgery, the proportion of positive ASD progression was comparable in the three treatment arms $(33 \%$ in the ACD group, $25 \%$ in the ACDF group and $31 \%$ in the ACDA group; $P=0.693$ ).

\section{Correlation between cervical sagittal alignment and radiological ASD}

In order to study the relationship between cervical sagittal alignment parameters and ASD, subjects were dichotomized according to the presence and progression of radiological $\mathrm{ASD}$, irrespective of the surgical method.

Table 4 Cervical sagittal alignment parameters with the presence and progression of ASD

\begin{tabular}{|c|c|c|c|c|c|c|c|c|c|}
\hline & ASD & Non-ASD & $P$ value & ASD & Mild ASD & $P$ value & $\begin{array}{l}\text { ASD positive } \\
\text { progression }\end{array}$ & $\begin{array}{l}\text { ASD negative } \\
\text { progression }\end{array}$ & $P$ value \\
\hline \multicolumn{10}{|l|}{ Baseline } \\
\hline Lordosis & $10.8 \pm 9.4$ & $11.6 \pm 9.0$ & 0.568 & $12.7 \pm 9.5$ & $11.1 \pm 9.1$ & 0.412 & - & - & - \\
\hline SVA & $22.7 \pm 12.4$ & $22.5 \pm 11.3$ & 0.884 & $25.8 \pm 11.3$ & $22.1 \pm 11.6$ & 0.122 & - & - & - \\
\hline T1 slope & $29.8 \pm 8.8$ & $29.5 \pm 9.5$ & 0.879 & $32.1 \pm 8.7$ & $29.2 \pm 9.3$ & 0.144 & - & - & - \\
\hline OCI & $107.7 \pm 9.0$ & $103.7 \pm 8.9$ & $0.007 *$ & $108.7 \pm 8.0$ & $104.4 \pm 9.1$ & $0.040^{*}$ & - & - & - \\
\hline \multicolumn{10}{|c|}{ 2-Year follow-up } \\
\hline Lordosis & $11.5 \pm 10.2$ & $14.8 \pm 10.5$ & 0.054 & $10.8 \pm 9.3$ & $13.7 \pm 10.7$ & 0.130 & $11.2 \pm 9.6$ & $14.7 \pm 11.0$ & 0.085 \\
\hline SVA & $23.2 \pm 11.1$ & $21.1 \pm 11.5$ & 0.270 & $24.8 \pm 11.8$ & $21.5 \pm 11.0$ & 0.118 & $23.2 \pm 11.5$ & $21.4 \pm 11.3$ & 0.423 \\
\hline T1 slope & $31.0 \pm 9.7$ & $32.1 \pm 9.6$ & 0.492 & $31.3 \pm 8.9$ & $31.5 \pm 9.9$ & 0.898 & $29.7 \pm 8.1$ & $32.5 \pm 10.1$ & 0.139 \\
\hline OCI & $109.0 \pm 10.1$ & $102.1 \pm 8.9$ & $<0.001 *$ & $112.9 \pm 9.3$ & $103.6 \pm 9.3$ & $<0.001 *$ & $109.1 \pm 11.3$ & $104.5 \pm 9.7$ & $0.020 *$ \\
\hline
\end{tabular}

$A S D$ adjacent segment degeneration, $S V A$ sagittal vertical axis, $O C I$ occipito-cervical inclination

$* P<0.05$ 
Table 5 Factors associated with the presence of ASD at baseline

\begin{tabular}{|c|c|c|c|c|c|c|c|}
\hline \multirow[t]{2}{*}{ Factors } & \multirow[t]{2}{*}{ Comparison } & \multicolumn{3}{|c|}{ Non-ASD versus ASD } & \multicolumn{3}{|c|}{ Mild ASD versus ASD } \\
\hline & & OR & $95 \% \mathrm{CI}$ & $P$ value & OR & $95 \% \mathrm{CI}$ & $P$ value \\
\hline Lordosis & Per additional degree & 0.99 & $0.96-1.02$ & 0.566 & 1.02 & $0.98-1.06$ & 0.411 \\
\hline SVA & Per additional $\mathrm{mm}$ & 1.00 & $0.98-1.02$ & 0.883 & 1.03 & $1.00-1.06$ & 0.124 \\
\hline OCI & Per additional degree & 1.05 & $1.01-1.09$ & $0.009^{*}$ & 1.05 & $1.00-1.11$ & $0.044 *$ \\
\hline T1 slope & Per additional degree & 1.00 & $0.97-1.04$ & 0.879 & 1.03 & $0.99-1.08$ & 0.145 \\
\hline
\end{tabular}

$A S D$ adjacent segment degeneration, $O R$ odds ratio, $S V A$ sagittal vertical axis, $O C I$ occipito-cervical inclination

$* P<0.05$

Table 6 Factors associated with the presence and progression of ASD at 2-year follow-up

\begin{tabular}{|c|c|c|c|c|c|c|c|c|c|c|}
\hline \multirow[t]{2}{*}{ Factors } & \multirow[t]{2}{*}{ Comparison } & \multicolumn{3}{|c|}{ Non-ASD versus ASD } & \multicolumn{3}{|c|}{ Mild ASD versus ASD } & \multicolumn{3}{|c|}{$\begin{array}{l}\text { ASD negative progression ver- } \\
\text { sus ASD positive progression }\end{array}$} \\
\hline & & OR & $95 \% \mathrm{CI}$ & $P$ value & OR & $95 \% \mathrm{CI}$ & $P$ value & OR & $95 \% \mathrm{CI}$ & $P$ value \\
\hline Lordosis & Per additional degree & 0.97 & $0.94-1.00$ & 0.057 & 0.97 & $0.93-1.01$ & 0.133 & 0.97 & $0.93-1.01$ & 0.089 \\
\hline SVA & Per additional mm & 1.02 & $0.99-1.05$ & 0.269 & 1.03 & $0.99-1.06$ & 0.120 & 1.01 & $0.98-1.05$ & 0.421 \\
\hline OCI & Per additional degree & 1.08 & $1.04-1.13$ & $<0.001 *$ & 1.11 & $1.06-1.16$ & $<0.001 *$ & 1.05 & $1.01-1.09$ & $0.023^{*}$ \\
\hline T1 slope & Per additional degree & 0.99 & $0.96-1.02$ & 0.490 & 1.00 & $0.96-1.04$ & 0.897 & 0.97 & $0.93-1.01$ & 0.14 \\
\hline
\end{tabular}

$A S D$ adjacent segment degeneration, $O R$ odds ratio, $S V A$ sagittal vertical axis, $O C I$ occipito-cervical inclination $* P<0.05$

The average values of sagittal alignment parameters of subjects with and without ASD are shown in Table 4.

At baseline, a higher OCI value was significantly correlated with the presence of ASD (OR 1.05; 95\% CI $1.01-1.09 ; P=0.009$ ). If patients were dichotomized into mild ASD and ASD, the result was similar (OR 1.05; 95\% CI 1.00-1.11; $P=0.044)$. C2-C7 lordosis, C2-C7 SVA and T1 slope failed to show a correlation with ASD (Table 5).

At 2-year follow-up, again, OCI with higher value was correlated with the presence of ASD (OR 1.08; 95\% CI 1.04-1.13; $P<0.001)$. If patients were dichotomized into mild ASD and ASD, the correlation between higher OCI and ASD was detected as well (OR 1.11; 95\% CI $1.06-1.16 ; P<0.001)$. Patients with higher OCI value were likewise correlated with the positive progression of ASD (OR 1.05; 95\% CI 1.01-1.09; $P=0.023$ ) (Table 6).

As stated above, no significant changes in mean OCI values existed between baseline and 2-year follow-up. On an individual level, changes were small for the vast majority of patients, but considerate for a minority of patients (Fig. 2). However, no correlation was demonstrated between the change in OCI value and the progression of ASD. Neither was there a correlation between the change in sagittal balance parameter and progression of ASD for the other parameters (Table 7).

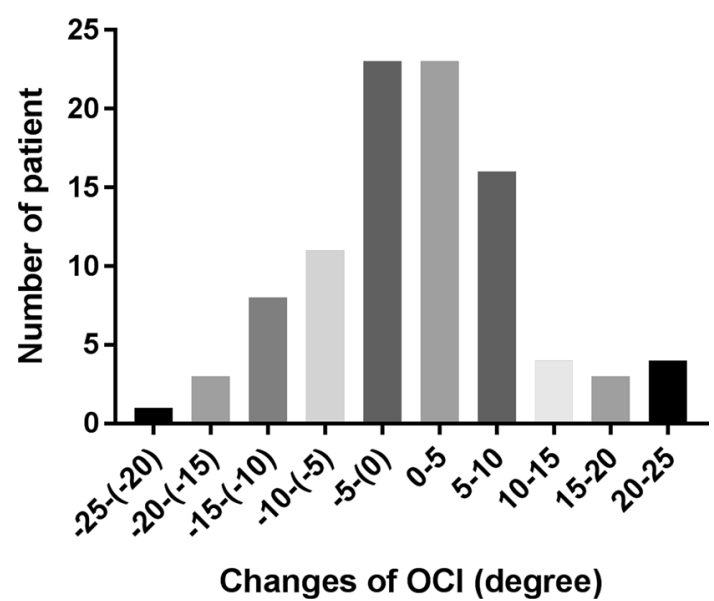

Fig. 2 Patient frequency of changes of OCI during 2 years after surgery

\section{Characteristics of clinical outcomes}

The clinical outcomes represented by NDI, PCS and MCS were comparable between the three treatment groups, both at baseline and at 2-year follow-up (Table 8). Therefore, the clinical outcomes were studied irrespective of surgical methods. At baseline, the mean NDI was $39.7 \pm 15.4$, mean PCS was $43.3 \pm 13.5$, and mean MCS was $59.1 \pm 21.5$. At 2 years after surgery, the NDI decreased to $16.4 \pm 17.1$. PCS and MCS increased to $73.9 \pm 23.6$ and $77.6 \pm 21.8$, respectively. 
Table 7 The change of sagittal alignment parameter associated with progression of ASD at 2-year follow-up

\begin{tabular}{llllll}
\hline $\begin{array}{l}\text { Association } \\
\text { between factors } \\
\text { and ASD }\end{array}$ & Comparison & \multicolumn{4}{l}{ Univariate analysis } \\
\cline { 3 - 5 } Lordosis changes & $\begin{array}{c}\text { Per additional } \\
\text { degree }\end{array}$ & 1.02 & $0.95-1.08$ & 0.618 \\
SVA changes & $\begin{array}{c}\text { Per additional mm } \\
\text { OCI changes }\end{array}$ & 1.01 & $0.95-1.08$ & 0.711 \\
Per additional & 1.07 & $0.99-1.16$ & 0.103 \\
T1 slope changes & $\begin{array}{c}\text { Per additional } \\
\text { degree }\end{array}$ & 1.02 & $0.93-1.13$ & 0.618 \\
\hline
\end{tabular}

$A S D$ adjacent segment degeneration, $O R$ odds ratio, SVA sagittal vertical axis, $O C I$ occipito-cervical inclination

Table 8 Characteristics of clinical outcome

\begin{tabular}{llll}
\hline & NDI & PCS & MCS \\
\hline Baseline & & & \\
ACD & $39.1 \pm 15.3$ & $42.4 \pm 13.3$ & $60.7 \pm 20.2$ \\
ACDF & $38.9 \pm 14.2$ & $44.7 \pm 12.2$ & $59.7 \pm 21.0$ \\
ACDA & $41.1 \pm 16.5$ & $42.9 \pm 14.0$ & $57.3 \pm 23.2$ \\
$P$ value & 0.589 & 0.591 & 0.639 \\
2-Year follow-up & & & \\
ACD & $16.3 \pm 14.4$ & $70.7 \pm 23.0$ & $74.4 \pm 22.9$ \\
ACDF & $16.0 \pm 16.9$ & $76.7 \pm 21.5$ & $81.6 \pm 19.2$ \\
ACDA & $16.9 \pm 19.6$ & $73.9 \pm 25.8$ & $76.5 \pm 22.8$ \\
$P$ value & 0.963 & 0.497 & 0.262 \\
\hline
\end{tabular}

$N D I$ neck disability index, $P C S$ physical-component summary, $M C S$ mental-component summary, $A C D$ anterior cervical discectomy, $A C D F$ anterior cervical discectomy with fusion, $A C D A$ anterior cervical discectomy with arthroplasty

\section{Correlation between cervical sagittal alignment and clinical outcomes}

At 2-year follow-up, the values of C2-C7 lordosis, C2-C7 SVA, OCI and T1 slope failed to correlate with clinical conditions, and neither was there a correlation of clinical outcome to the changes of these parameters $(P>0.05)$.

\section{Correlation between cervical sagittal alignments}

SVA was significantly correlated with $\mathrm{T} 1$ slope $(0.45-0.54$, $P<0.01)$ and OCI $(0.20-0.37, P<0.01)$. C2-C7 lordosis was correlated with T1 slope as well $(0.40-0.55, P<0.01)$ (Table 9).
Table 9 Correlation between sagittal alignment parameters

\begin{tabular}{lllll}
\hline & Lordosis & SVA & T1 slope & OCI \\
\hline Baseline & & & & \\
Lordosis & - & -0.11 & $0.40^{* *}$ & -0.01 \\
SVA & - & - & $0.45^{* *}$ & $0.20^{* *}$ \\
T1 slope & - & - & - & 0.01 \\
OCI & - & - & - & - \\
1 year & & & & \\
Lordosis & - & 0.03 & $0.55^{* *}$ & 0.05 \\
SVA & - & - & $0.54^{* *}$ & $0.35^{* *}$ \\
T1 slope & - & - & - & $0.16^{*}$ \\
OCI & - & - & - & - \\
2 years & & & & $0.20^{*}$ \\
Lordosis & - & 0.03 & $0.53^{* *}$ & $0.37^{* *}$ \\
SVA & - & - & $0.53^{* *}$ & 0.04 \\
T1 slope & - & - & - & - \\
OCI & - & - & - & \\
\hline
\end{tabular}

*Correlation is significant at the 0.05 level (2-tailed), **correlation is significant at the 0.01 level (2-tailed)

\section{Discussion}

Cervical sagittal alignment was demonstrated not to be affected by anterior discectomy during 2-year follow-up after surgery. The alleged superiority of maintaining cervical alignment in arthroplasty was not established. The occipitocervical angle, being crucial in maintaining horizontal gaze, was identified as an important factor associated with radiological adjacent segment degeneration.

OCI is a relatively new radiological parameter of the angle between the occiput and the cervical spine proposed by Yoon et al. [6]. In this study, it is first applied to investigate the relationship with radiological ASD and clinical outcomes in patients with cervical disc degeneration. $\mathrm{Wu}$ et al. [20] reported before that the occipito-C2 angle was correlated with post-operative ASD in a patient group that underwent occipitoaxial spondylodesis. Theoretically, the occipito-cervical angle is dictated by horizontal gaze, and if this angle is imbalanced, it may well lead to compensation of subaxial cervical curvature, which will eventually lead to accelerated degeneration of the cervical spine [21]. This could explain the strong correlation of OCI with ASD detected in this study.

Remarkably, the OCI angle did not change after surgery, although there was significantly more ASD in patients with a higher OCI. Therefore, the result of this study suggests that accelerated degeneration of the cervical spine is dictated by the OCI angle. Thus, accelerated degeneration of the cervical (subaxial) spine can be predicted if the OCI is known. Ideally, a cut-off point of the OCI would be available. ASD is determined in this study in 
three ways, and therefore, three different values are available: for non-ASD, an angle of $102^{\circ}-104^{\circ}$ was measured, and for ASD angles, varying between $108^{\circ}$ and $113^{\circ}$ were observed (Table 4). Future studies are needed to confirm and determine cut-off values. Moreover, long-term followup studies are needed to study whether ASD or subaxial degeneration continues during longer follow-up or that it stabilizes.

In the current study, no correlation between clinical outcome and sagittal balance parameters could be demonstrated. The C2-C7 SVA and T1 slope did not change in follow-up of surgery, the $\mathrm{C} 2-\mathrm{C} 7$ lordosis only increased minimally, and they did not demonstrate a correlation with ASD. Therefore, an absence of correlation with the clinical outcome is not surprising. However, previous studies did demonstrate an association between sagittal alignment parameters to the quality of life [1, 22]. Tang et al. [23] found that the C2-C7 SVA was negatively correlated with PCS and positively correlated with NDI scores after multilevel cervical posterior fusion. Hyun et al. [24] found that C2-C7 SVA greater than $43.5 \mathrm{~mm}$ was corresponded to severe NDI (>25). Nevertheless, Jeon et al. [3] and Kwon et al. [25], which compared similar radiographic parameters with NDI and visual analog scale (VAS), reported that no cervical sagittal alignment parameters were significantly correlated with clinical outcomes after ACDF surgery with 3 levels and 2 levels, respectively, which are consistent with our results. It has to be noted though that these authors describe different surgical approaches. Tang et al. [23] and Hyun et al. [24] reported on patients with posterior cervical fusion surgery. Jeon et al. [3] and Kwon et al. [25] reported on multilevel anterior fusion surgery of the cervical spine and demonstrated threshold values for C2-C7 SVA of $40 \mathrm{~mm} \mathrm{[23]} \mathrm{and} 43.5 \mathrm{~mm}$ [24] in contrast to the values that we reported in the majority of patients (mean value $20.6-22.5 \mathrm{~mm}$ ).

A limitation of this study is that we have analysed radiographic parameters with a follow-up of only 2 years after surgery. In contrast to our results, other research groups did demonstrate a lower occurrence of ASD in ACDA compared with ACDF with longer follow-up periods [26-30]. These articles, however, had a high or intermediate risk of bias, and estimates of effect were not sufficiently described. Therefore, the level of evidence that ASD occurs more often in ACDF than in ACDA is low [31]. Moreover, a recent study with low risk of bias demonstrated that the presence of both clinical ASD and radiological ASD was similar in the ACDA and ACDF at 5-year follow-up [32]. It is thus debatable whether ASD will demonstrate differences between the three groups upon longer follow-up periods. However, in our opinion, the current data on ASD, demonstrating a gradual increase in ASD in all three groups, make this rather unlikely.

\section{Conclusion}

The choice of the intervertebral device in anterior cervical discectomy surgery does not influence cervical sagittal alignment. OCI was demonstrated to be an important factor associated with radiological ASD, suggesting that occipito-cervical alignment influences accelerated cervical degeneration. The correlation between cervical sagittal alignment parameters and clinical outcome is absent.

Funding This work was supported by China Scholarship Council and the Department of Neurosurgery, Leiden University Medical Centre. Xiaoyu Yang received support from both funding agencies. The NECK trial was sponsored by B. Braun Medical and the Department of Neurosurgery, Leiden University Medical Centre, The Netherlands.

\section{Compliance with ethical standards}

Conflict of interest There is no conflict of interest for the current study.

Ethical approval All procedures performed in studies involving human participants were in accordance with the ethical standards of the institutional and/or national research committee and with the 1964 Helsinki declaration and its later amendments or comparable ethical standards.

Open Access This article is distributed under the terms of the Creative Commons Attribution 4.0 International License (http://creativeco mmons.org/licenses/by/4.0/), which permits unrestricted use, distribution, and reproduction in any medium, provided you give appropriate credit to the original author(s) and the source, provide a link to the Creative Commons license, and indicate if changes were made.

\section{References}

1. Scheer JK, Tang JA, Smith JS, Acosta FL Jr, Protopsaltis TS, Blondel B, Bess S, Shaffrey CI, Deviren V, Lafage V, Schwab F, Ames CP (2013) Cervical spine alignment, sagittal deformity, and clinical implications: a review. J Neurosurg Spine 19:141159. https://doi.org/10.3171/2013.4.spine 12838

2. Ames CP, Blondel B, Scheer JK, Schwab FJ, Le Huec JC, Massicotte EM, Patel AA, Traynelis VC, Kim HJ, Shaffrey CI, Smith JS, Lafage V (2013) Cervical radiographical alignment: comprehensive assessment techniques and potential importance in cervical myelopathy. Spine 38:S149-S160. https://doi. org/10.1097/BRS.0b013e3182a7f449

3. Jeon SI, Hyun SJ, Han S, Lee BH, Kim KJ, Jahng TA, Kim HJ (2018) Relationship between cervical sagittal alignment and patient outcomes after anterior cervical fusion surgery involving 3 or more levels. World Neurosurg 113:e548-e554. https://doi. org/10.1016/j.wneu.2018.02.088

4. Hyun SJ, Kim KJ, Jahng TA, Kim HJ (2016) Relationship between $\mathrm{T} 1$ slope and cervical alignment following multilevel posterior cervical fusion surgery: impact of $\mathrm{T} 1$ slope minus cervical lordosis. Spine 41:E396-E402. https://doi.org/10.1097/ brs.0000000000001264

5. Knott PT, Mardjetko SM, Techy F (2010) The use of the T1 sagittal angle in predicting overall sagittal balance of the 
spine. Spine J 10:994-998. https://doi.org/10.1016/j.spine e.2010.08.031

6. Yoon SD, Lee CH, Lee J, Choi JY, Min WK (2017) Occipitocervical inclination: new radiographic parameter of neutral occipitocervical position. Eur Spine J 26:2297-2302. https:// doi.org/10.1007/s00586-017-5161-0

7. Smith GW, Robinson RA (1958) The treatment of certain cervical-spine disorders by anterior removal of the intervertebral disc and interbody fusion. J Bone Joint Surg Am 40-a:607-624

8. Bartels R, Goffin J (2018) Albert Dereymaeker and Joseph Cyriel Mulier's description of anterior cervical discectomy with fusion in 1955. J Neurosurg Spine 28:395-400. https://doi. org/10.3171/2017.7.Spine17182

9. Goffin J, van Loon J, Van Calenbergh F, Lipscomb B (2010) A clinical analysis of 4- and 6-year follow-up results after cervical disc replacement surgery using the Bryan Cervical Disc Prosthesis. J Neurosurg Spine 12:261-269. https://doi. org/10.3171/2009.9.Spine09129

10. Kim SW, Limson MA, Kim SB, Arbatin JJ, Chang KY, Park MS, Shin JH, Ju YS (2009) Comparison of radiographic changes after ACDF versus Bryan disc arthroplasty in single and bi-level cases. Eur Spine J 18:218-231. https://doi.org/10.1007/s0058 6-008-0854-z

11. Donk RD, Arnts H, Verhagen WIM, Groenewoud H, Verbeek A, Bartels R (2017) Cervical sagittal alignment after different anterior discectomy procedures for single-level cervical degenerative disc disease: randomized controlled trial. Acta Neurochir (Wien) 159:2359-2365. https://doi.org/10.1007/s00701-017-3312-z

12. Sasso RC, Metcalf NH, Hipp JA, Wharton ND, Anderson PA (2011) Sagittal alignment after Bryan cervical arthroplasty. Spine 36:991-996. https://doi.org/10.1097/BRS.0b013e3182076d70

13. Arts MP, Brand R, van den Akker E, Koes BW, Peul WC (2010) The NEtherlands Cervical Kinematics (NECK) trial. Cost-effectiveness of anterior cervical discectomy with or without interbody fusion and arthroplasty in the treatment of cervical disc herniation; a double-blind randomised multicenter study. BMC Musculoskelet Disord 11:122. https://doi.org/10.1186/1471-2474-11-122

14. Vleggeert-Lankamp CLA, Janssen TMH, van Zwet E, Goedmakers CMW, Bosscher L, Peul W, Arts MP (2018) The NECK trial: effectiveness of anterior cervical discectomy with or without interbody fusion and arthroplasty in the treatment of cervical disc herniation; a double-blinded randomized controlled trial. Spine J. https://doi.org/10.1016/j.spinee.2018.12.013

15. Bartels RH, Donk R, van der Wilt GJ, Grotenhuis JA, Venderink D (2006) Design of the PROCON trial: a prospective, randomized multi-center study comparing cervical anterior discectomy without fusion, with fusion or with arthroplasty. BMC Musculoskelet Disord 7:85. https://doi.org/10.1186/1471-2474-7-85

16. Donk RD, Verbeek ALM, Verhagen WIM, Groenewoud H, Hosman AJF, Bartels R (2017) What's the best surgical treatment for patients with cervical radiculopathy due to single-level degenerative disease? A randomized controlled trial. PLoS ONE 12:e0183603. https://doi.org/10.1371/journal.pone.0183603

17. Tamai K, Buser Z, Paholpak P, Sessumpun K, Nakamura H, Wang JC (2018) Can C7 slope substitute the T1 slope?: an analysis using cervical radiographs and kinematic MRIs. Spine 43:520-525. https://doi.org/10.1097/brs.0000000000002371

18. Goffin J, Geusens E, Vantomme N, Quintens E, Waerzeggers Y, Depreitere B, Van Calenbergh F, van Loon J (2004) Long-term follow-up after interbody fusion of the cervical spine. J Spinal Disord Tech 17:79-85

19. Vos CJ, Verhagen AP, Koes BW (2006) Reliability and responsiveness of the Dutch version of the Neck Disability Index in patients with acute neck pain in general practice. Eur Spine J 15:1729-1736. https://doi.org/10.1007/s00586-006-0119-7
20. Wu X, Qi Y, Tan M, Yi P, Yang F, Tang X, Hao Q (2018) Incidence and risk factors for adjacent segment degeneration following occipitoaxial fusion for atlantoaxial instability in non-rheumatoid arthritis. Arch Orthop Trauma Surg 138:921-927. https:// doi.org/10.1007/s00402-018-2929-6

21. Amabile C, Le Huec J-C, Skalli W (2018) Invariance of headpelvis alignment and compensatory mechanisms for asymptomatic adults older than 49 years. Eur Spine J 27:458-466. https://doi. org/10.1007/s00586-016-4830-8

22. Roguski M, Benzel EC, Curran JN, Magge SN, Bisson EF, Krishnaney AA, Steinmetz MP, Butler WE, Heary RF, Ghogawala Z (2014) Postoperative cervical sagittal imbalance negatively affects outcomes after surgery for cervical spondylotic myelopathy. Spine 39:2070-2077. https://doi.org/10.1097/brs.0000000000 000641

23. Tang JA, Scheer JK, Smith JS, Deviren V, Bess S, Hart RA, Lafage V, Shaffrey CI, Schwab F, Ames CP (2015) The impact of standing regional cervical sagittal alignment on outcomes in posterior cervical fusion surgery. Neurosurgery 76(Suppl 1):S14-S21. https ://doi.org/10.1227/01.neu.0000462074.66077.2b (discussion S21)

24. Hyun SJ, Kim KJ, Jahng TA, Kim HJ (2017) Clinical impact of T1 slope minus cervical lordosis after multilevel posterior cervical fusion surgery: a minimum 2-year follow up data. Spine 42:1859-1864. https://doi.org/10.1097/brs.0000000000002250

25. Kwon WK, Kim PS, Ahn SY, Song JY, Kim JH, Park YK, Kwon TH, Moon HJ (2017) Analysis of associating factors with C2-7 sagittal vertical axis after two-level anterior cervical fusion: comparison between plate augmentation and stand-alone cages. Spine 42:318-325. https://doi.org/10.1097/brs.0000000000001776

26. Coric D, Nunley PD, Guyer RD, Musante D, Carmody CN, Gordon CR, Lauryssen C, Ohnmeiss DD, Boltes MO (2011) Prospective, randomized, multicenter study of cervical arthroplasty: 269 patients from the Kineflex|C artificial disc investigational device exemption study with a minimum 2-year followup: clinical article. J Neurosurg Spine 15:348-358. https://doi. org/10.3171/2011.5.spine10769

27. Phillips FM, Geisler FH, Gilder KM, Reah C, Howell KM, McAfee PC (2015) Long-term outcomes of the US FDA IDE prospective, randomized controlled clinical trial comparing PCM cervical disc arthroplasty with anterior cervical discectomy and fusion. Spine 40:674-683. https://doi.org/10.1097/brs.000000000000086 9

28. Hisey MS, Zigler JE, Jackson R, Nunley PD, Bae HW, Kim KD, Ohnmeiss DD (2016) Prospective, randomized comparison of one-level Mobi-C cervical total disc replacement vs. anterior cervical discectomy and fusion: results at 5-year follow-up. Int J Spine Surg 10:10. https://doi.org/10.14444/3010

29. Sun Y, Zhao YB, Pan SF, Zhou FF, Chen ZQ, Liu ZJ (2012) Comparison of adjacent segment degeneration five years after single level cervical fusion and cervical arthroplasty: a retrospective controlled study. Chin Med J 125:3939-3941

30. Davis RJ, Nunley PD, Kim KD, Hisey MS, Jackson RJ, Bae HW, Hoffman GA, Gaede SE, Danielson GO 3rd, Gordon C, Stone MB (2015) Two-level total disc replacement with Mobi-C cervical artificial disc versus anterior discectomy and fusion: a prospective, randomized, controlled multicenter clinical trial with 4-year follow-up results. J Neurosurg Spine 22:15-25. https://doi. org/10.3171/2014.7.spine 13953

31. Yang X, Janssen T, Arts MP, Peul WC, Vleggeert-Lankamp CLA (2018) Radiological follow-up after implanting cervical disc prosthesis in anterior discectomy: a systematic review. The spine journal: official journal of the North American Spine Society 18:1678-1693. https://doi.org/10.1016/j.spinee.2018.04.021

32. MacDowall A, Canto Moreira N, Marques C, Skeppholm M, Lindhagen L, Robinson Y, Lofgren H, Michaelsson K, Olerud C (2019) Artificial disc replacement versus fusion in patients 
with cervical degenerative disc disease and radiculopathy: a randomized controlled trial with 5-year outcomes. J Neurosurg Spine 30:323-331. https://doi.org/10.3171/2018.9.Spine18659
Publisher's Note Springer Nature remains neutral with regard to jurisdictional claims in published maps and institutional affiliations.

\section{Affiliations}

\section{Xiaoyu Yang ${ }^{1}$ (1) $\cdot$ Ronald H. M. A. Bartels ${ }^{2} \cdot$ Roland Donk $^{3} \cdot$ Mark P. Arts $^{4} \cdot$ Caroline M. W. Goedmakers $^{1}$.}

\section{Carmen L. A. Vleggeert-Lankamp ${ }^{1}$}

Xiaoyu Yang

X.Yang@lumc.nl

1 J11-R-83: Department of Neurosurgery, Leiden University Medical Centre, Albinusdreef 2, 2300 RC Leiden,

The Netherlands

2 Department of Neurosurgery, Radboud University Medical Centre, Nijmegen, The Netherlands
3 Department of Orthopaedic Surgery, Via Sana Clinics, Mill, The Netherlands

4 Department of Neurosurgery, Haaglanden Medical Centre, The Hague, The Netherlands 